www.jmscr.igmpublication.org

Impact Factor 5.84

Index Copernicus Value: 71.58

ISSN (e)-2347-176x ISSN (p) 2455-0450

crossref DOI: _https://dx.doi.org/10.18535/jmscr/v6i1.168

Journal Of Medical Science And Clinical Research

\title{
Quality of Life among Post-Menopausal Women in Rural area of Punjab
}

\author{
Authors \\ Dr Deepshikha Karma, Dr Shipra Saini, Dr Shavinder Singh \\ Corresponding Author \\ Dr Deepshikha Kamra Sehgal
}

Associate Professor, Dept. of Community Medicine, Christian Medical College, Ludhiana, Punjab

\begin{abstract}
Background: Menopause is a physiological process in women's life. The transition through menopause is a life event that can profoundly affect quality of life.

Aims \& Objectives: To assess the menopausal related symptoms and their impact on the women's quality of life. To find out association of menopausal symptom domains with their socio-demographic parameters.

Methods: This cross-sectional study was conducted in 2017 on 100 postmenopausal women. We used the Menopause-Specific QOL questionnaire (MENQOL) for measuring QOL in postmenopausal women. Epidata analysis Version 2.2.2 was used for data analysis.

Results: The mean menopausal age was $45.80 \pm 4.49$ years. The overall mean scores obtained for each domain was $3.11+1.1$ in vasomotor domain, $2.89+1.3$ in psychosocial domain, $2.75+1.5$ physical domain and 2.05+1.7 in sexual domain. Our findings showed that menopausal women had worse QOL in vasomotor domain and psychosocial domain.

Conclusion: A large proportion of postmenopausal women suffered from menopausal symptoms. The most common menopausal complaints reported by the postmenopausal women were feeling tired, decrease stamina, changes in appearance, texture or tone of skin, aching in muscle and joints and experiencing poor memory. Sexual life was also affected by menopause.

Keywords: Menopause Quality of life, Vasomotor, Physical, Psychosocial.
\end{abstract}

\section{Introduction}

Menopause is a universal event in a women's life causing a variety of physical, vasomotor, psychological and sexual symptoms. It is cessation of periods for 12 months or cessation of ovarian function resulting in permanent amenorrhoea. ${ }^{[1,2]}$ It usually occurs more or less in midlife, signaling the end of the reproductive phase of a women's life.

There is a drop in the levels of estrogen and progesterone, the two most important hormones in the female body (World Health Organization
[WHO], 1996). The onset of this physiological development not only marks the end of women's reproductive function but also introduces them to a new phase of life. ${ }^{[3]}$

With the advent of modern medicine, there is a general increase in life expectancy, thus many women spends almost $1 / 3 \mathrm{rd}$ of life in menopause, in an estrogen deficient state. ${ }^{[4]}$

According to the World Health Organization in 1990, about 25 million women worldwide reached menopause, this number is expected to double by the late 2020s. ${ }^{[5]}$ 
The average age of menopause is around 48 years, but it strikes Indian women as young as 30-35 years. Due to the increase in the life expectancy women will have to face longer periods of menopause. ${ }^{[6]}$

According to Indian Menopause Society, there were about 65 million Indian women over the age of 45 years in the year 2006. Hence, menopausal health demands even higher priority in Indian scenario. ${ }^{[7]}$

The transition through menopause is a life event that can profoundly affect quality of life. More than $80 \%$ of women report physical and psychological symptoms that commonly accompany menopause, with varying degrees of severity and life disruption. ${ }^{[8]}$

These symptoms usually tend to go underreported. In India, there is no current health program that caters to the specific health needs of postmenopausal women. Moreover, Reproductive and Child Health-II and National Rural Health Mission only addresses women in the reproductive age group, ignoring those who have passed their reproductive stage. ${ }^{[9]}$

There is an urgent need to focus our health services to postmenopausal women, as maintaining good physical functioning with age is a vital component of independence in later life. This study is expected to bring out the magnitude of suffering due to health issues among postmenopausal women and association of health issues with various sociodemographic factors.

\section{Aims \& Objectives}

The aim of this study was to assess the menopausal related symptoms and their impact on the women's quality of life. To find out association of menopausal symptom domains with their socio-demographic parameters.

\section{Material \& Methods}

The present cross-sectional study was undertaken in urban field practice area of department of Community Medicine, CMC Ludhiana.
The sample size of 100 was calculated, taking $36.7 \%$ prevalence $^{[10]}$ of vasomotor symptoms (flushing and night sweat) with acceptable error of $10 \%$ at $95 \%$ confidence interval (CI) the sample size of 100 was taken. Menopause was defined by 12 months of amenorrhea after the final menstrual period. ${ }^{[11]}$

The questionnaire had two parts.

Part 1: Sociodemographic characteristics

Part 2: MENQOL questionnaire for Quality of Life: It is self-administered and consists of a total of 29 items. Each item assesses the impact of one of four domains of menopausal symptoms, as experienced over the last month: Vasomotor (items 1-3), psychosocial (items 4-10), physical (items 11-26), and sexual (items 27-29). Items pertaining to a specific symptom are rated as present or not present, and if present, how bothersome on a zero (not bothersome) to six (extremely bothersome) point scale. Means are computed for each subscale by dividing the sum of the domain's items by the number of items within that domain.

All postmenopausal women living in the study area who satisfied the inclusion and exclusion criteria were included in the study.

Inclusion criteria Inclusion criteria for the study were postmenopausal women with at least 1 year of amenorrhea and those who had attained natural menopause in last 5 years, to minimize recall bias. Exclusion criteria Postmenopausal women with a known history of chronic diseases such as hypertension, diabetes, migraine, cardiovascular disease, tumors, tuberculosis, rheumatoid arthritis, and osteoarthritis were excluded from the study.

Women with induced menopause, simple hysterectomy, receiving any kind of hormone therapy, presence of medical conditions such as diabetes, hypertension, cardiac disease, and thyroid disorders

Locked houses or the women who did not give the consent were not included in the study.

\section{Ethical consideration}

Informed consent was obtained from each participant. The significant and purpose of the 
study was explained to women. The participants were assured that any information, obtained will be treated with utmost confidentiality.

\section{Statistical Design}

Data was collected, coded, tabulated and analyzed, using the epidata entry and Epidata analysis Version 2.2.2. Descriptive statistics was used to calculate percentages, frequencies, Mean and standard deviations, Chi square, $t$ test are used to estimate the statistical significant differences. A significant $\mathrm{p}$ value was considered when $\mathrm{p}$ less than 0.05 and it was considered highly significant when pvalue less than or equal 0.01 .

\section{Results}

The mean age of the women was $53.89 \pm 5.26$ years and the mean menopausal age was $45.80 \pm 4.49$ years. $92 \%$ belonged to Sikh community. Majority (96\%) were housewives and $60 \%$ were literate. Most of them (61\%) lived in joint family. Majority of women (72\%) had more than 2 children and $88 \%$ had history of abortion. Forty five percent of women belonged to low socio- economic status.

Table 1 Characteristics of postmenopausal women

\begin{tabular}{|l|c|}
\hline Characteristics & $\mathrm{N}=100$ \\
\hline Age & 19 \\
\hline$<50$ & 81 \\
\hline$>=50$ & \\
\hline Religion & 8 \\
\hline Hindu & 92 \\
\hline Sikh & \\
\hline Education & 40 \\
\hline Illiterate & 60 \\
\hline Literate & \\
\hline Employement & 96 \\
\hline Housewife & 4 \\
\hline Working & \\
\hline Type of Family & 61 \\
\hline Joint & 39 \\
\hline Nuclear & \\
\hline Number of Children & 28 \\
\hline$<=2$ & 72 \\
\hline$>2$ & \\
\hline Socioeconomic status & 55 \\
\hline High & 45 \\
\hline low & \\
\hline
\end{tabular}

Occurrence of vasomotor symptoms was average with $48 \%$ of them reporting hot flushes and $39 \%$ reporting sweating. Physical symptoms of menopause were found highly variable, from decreased stamina and feeling lack of energy $89 \%$ to Involuntary urination while laughing or coughing $24 \%$. Sexual symptoms were mild but were the most prevalent with change in sexual desire $(84 \%)$, vaginal dryness during intimacy $(52 \%)$ and avoiding intimacy to be $(82 \%)$.

Table 2: Mean Scores of MENQOL items

\begin{tabular}{|l|c|c|}
\hline Symptoms & N & Mean \pm SD \\
\hline Vasomotor & & \\
\hline Hot flushes & 48 & $3.36 \pm 1.12$ \\
\hline Night sweats & 32 & $3.13 \pm 1.13$ \\
\hline Sweating & 39 & $3.05 \pm 1.12$ \\
\hline Psycosocial & & \\
\hline Dissatisfaction with personal life & 48 & $2.73 \pm 1.16$ \\
\hline Feeling anxious or nervous & 53 & $3.15 \pm 1.41$ \\
\hline Experiencing poor memory & 64 & $4.34 \pm 1.03$ \\
\hline Accomplishing less than I used to & 39 & $2.97 \pm 1.22$ \\
\hline Feeling depressed, down, blue & 54 & $3.13 \pm 1.40$ \\
\hline Impatience with other people & 55 & $3.04 \pm 1.36$ \\
\hline Willing to be alone & 45 & $3.57 \pm 1.62$ \\
\hline Physical & & \\
\hline Flatulance / gas pain & 53 & $2.62 \pm 1.33$ \\
\hline Aching in muscle and joints & 69 & $3.07 \pm 1.40$ \\
\hline Feeling tired or worn out & 88 & $3.39 \pm 1.40$ \\
\hline Difficulty in sleeping & 33 & $2.58 \pm 1.58$ \\
\hline Aches in back of neck or head & 42 & $2.33 \pm 1.44$ \\
\hline Decrease in physical strength & 89 & $3.30 \pm 1.52$ \\
\hline Decreased stamina & 89 & $3.33 \pm 1.48$ \\
\hline Feeling lack of energy & 89 & $3.34 \pm 1.47$ \\
\hline Dry skin & 56 & $2.77 \pm 1.04$ \\
\hline Facial Hair & 29 & $2.52 \pm 1.50$ \\
\hline Weight gain & 38 & $2.39 \pm 1.52$ \\
\hline $\begin{array}{l}\text { Changes in appearance, texture or } \\
\text { tone of skin }\end{array}$ & 70 & $1.89 \pm 0.91$ \\
\hline Feeling bloated & 50 & $2.36 \pm 1.21$ \\
\hline Low backache & 42 & $2.83 \pm 1.32$ \\
\hline Frequent urination & 29 & $2.52 \pm 1.50$ \\
\hline $\begin{array}{l}\text { Involuntary urination } \\
\text { laughing or coughing }\end{array}$ & 24 & $2.42 \pm 1.44$ \\
\hline Sexual & & \\
\hline Change in sexual desire & 84 & $2.43 \pm 1.68$ \\
\hline Vaginal dryness during intimacy & 52 & $2.01 \pm 1.40$ \\
\hline Avoiding intimacy & 82 & $2.15 \pm 1.80$ \\
\hline & & \\
\hline
\end{tabular}

Highest mean scores of symptoms in vasomotor, psychosocial, physical and sexual domains were hot flushes $(3.36 \pm 1.12)$, experiencing poor memory (4.34 \pm 1.03$)$, Feeling tired or worn out $(3.39 \pm 1.40)$ and change in sexual desire $(2.43 \pm$ 
1.68) respectively. Table 2 indicated that the highest mean scores of symptoms in vasomotor, psychosocial, physical and sexual domains were, hot flush (3.36 \pm 1.12$)$, willing to be alone (3.57 \pm $1.62)$, feeling tired or worn out $(3.39 \pm 1.40)$, change in sexual desire $(2.43 \pm 1.68)$ respectively.

Table 3: Distribution of the postmenopausal women according to severity of menopausal symptoms

\begin{tabular}{|c|c|c|c|c|c|c|c|}
\hline \multirow{2}{*}{$\begin{array}{l}\text { Symptoms } \\
\text { Vasomotor }\end{array}$} & \multirow[t]{2}{*}{$\mathbf{N}$} & \multicolumn{2}{|c|}{ Mild } & \multicolumn{2}{|c|}{ Moderate } & \multicolumn{2}{|c|}{ Severe } \\
\hline & & & & & & & \\
\hline Hot flushes & 48 & 15 & 31.4 & 22 & 45.7 & 11 & 22.9 \\
\hline Night sweats & 32 & 8 & 25 & 20 & 62.5 & 4 & 12.5 \\
\hline Sweating & 39 & 11 & 28.2 & 24 & 61.5 & 4 & 10.3 \\
\hline \multicolumn{8}{|l|}{ Psycosocial } \\
\hline Dissatisfaction with personal life & 48 & 22 & 45.8 & 22 & 45.8 & 4 & 8.3 \\
\hline Feeling anxious or nervous & 53 & 21 & 39.6 & 21 & 39.6 & 11 & 20.8 \\
\hline Experiencing poor memory & 64 & 2 & 3.1 & 28 & 43.8 & 34 & 53.1 \\
\hline Accomplishing less than I used to & 39 & 6 & 15.4 & 18 & 46.2 & 15 & 38.5 \\
\hline Feeling depressed, down, blue & 54 & 20 & 37 & 23 & 42.6 & 11 & 20.4 \\
\hline Impatience with other people & 55 & 21 & 38.2 & 24 & 43.6 & 10 & 18.2 \\
\hline Willing to be alone & 45 & 15 & 33.3 & 18 & 40 & 12 & 26.4 \\
\hline \multicolumn{8}{|l|}{ Physical } \\
\hline Flatulance / gas pain & 53 & 30 & 56.6 & 6 & 11.3 & 17 & 32.1 \\
\hline Aching in muscle and joints & 69 & 28 & 40.6 & 14 & 20.3 & 27 & 39.1 \\
\hline Feeling tired or worn out & 88 & 24 & 27.3 & 25 & 28.4 & 39 & 44.3 \\
\hline Difficulty in sleeping & 33 & 7 & 21.2 & 21 & 63.6 & 5 & 15.2 \\
\hline Aches in back of neck or head & 42 & 25 & 59.5 & 5 & 11.9 & 12 & 28.6 \\
\hline Decrease in physical strength & 89 & 25 & 28.1 & 41 & 46.1 & 23 & 25.8 \\
\hline Decreased stamina & 89 & 25 & 28.1 & 41 & 46.1 & 23 & 25.8 \\
\hline Feeling lack of energy & 89 & 24 & 27 & 42 & 47.2 & 23 & 25.8 \\
\hline Dry skin & 56 & 46 & 82.1 & 1 & 1.8 & 9 & 16.1 \\
\hline Facial Hair & 29 & 17 & 58.6 & 5 & 17.2 & 7 & 24.1 \\
\hline Weight gain & 38 & 24 & 63.2 & 5 & 13.2 & 9 & 23.7 \\
\hline Changes in appearance, texture or tone of skin & 70 & 56 & 80 & 12 & 17.1 & 2 & 2.9 \\
\hline Feeling bloated & 50 & 31 & 62 & 5 & 10 & 14 & 28 \\
\hline Low backache & 42 & 17 & 40.5 & 18 & 42.9 & 7 & 18.7 \\
\hline Frequent urination & 29 & 17 & 58.6 & 7 & 24.1 & 5 & 17.2 \\
\hline Involuntary urination while laughing or coughing & 24 & 15 & 62.5 & 7 & 29.2 & 2 & 8.3 \\
\hline \multicolumn{8}{|l|}{ Sexual } \\
\hline Change in sexual desire & 84 & 60 & 71.4 & 8 & 9.5 & 16 & 19.1 \\
\hline Vaginal dryness during intimacy & 52 & 40 & 76.9 & 7 & 13.5 & 5 & 9.6 \\
\hline Avoiding intimacy & 82 & 66 & 80.5 & 6 & 7.3 & 10 & 12.2 \\
\hline
\end{tabular}

Table 4 illustrated the overall scores of menopausal quality of life for each MENQOL domain. It was observed that the highest mean score in vasomotor domain $(3.11 \pm 1.1)$ followed by psychosocial $(2.89 \pm 1.3)$ then physical symptoms $(2.75 \pm 1.5)$ and finally sexual domain $(2.05 \pm 1.7)$.

The overall scores of menopausal quality of life for each domain was observed and was found the highest mean score in, followed by psychosocial.
Table 4: Mean Score for each MENQOL domain

\begin{tabular}{|l|c|}
\hline Domain & Mean \pm SD \\
\hline Vasomotor & $3.11 \pm 1.1$ \\
\hline Psycological & $2.89 \pm 1.3$ \\
\hline Pysical & $2.75 \pm 1.5$ \\
\hline Sexual & $2.05 \pm 1.7$ \\
\hline
\end{tabular}


Table 5: Mean scores per domain in menopausal women according to socio-demographic characteristics

\begin{tabular}{|l|c|c|c|c|}
\hline & Vasomotor & Psycological & Physical & Sexual \\
\hline Age & & & & \\
\hline$<50$ & $2.57 \pm 1.35$ & $1.83 \pm 0.9$ & $1.61 \pm 0.7$ & $1.88 \pm 1.59$ \\
\hline$>=50$ & $2.65 \pm 1.33$ & $1.53 \pm 1.1$ & $1.54 \pm 0.9$ & $2.04 \pm 1.71$ \\
\hline & $\mathrm{p}=0.9$ & $\mathrm{p}=0.3$ & $\mathrm{p}=0.7$ & $\mathrm{p}=0.71$ \\
\hline Religion & & & & \\
\hline Hindu & $1.10 \pm 0.6$ & $1.51 \pm 1.02$ & $1.54 \pm 0.8$ & $5.80 \pm 2.41$ \\
\hline Sikh & $2.79 \pm 1.28$ & $1.59 \pm 1.15$ & $1.55 \pm 0.9$ & $1.92 \pm 1.61$ \\
\hline & $\mathrm{p}=\mathbf{0 . 0 1}$ & $\mathrm{p}=0.8$ & $\mathrm{p}=0.9$ & $\mathrm{p}=\mathbf{0 . 0 3}$ \\
\hline Education & & & & \\
\hline Illiterate & $2.71 \pm 1.29$ & $1.66 \pm 1.09$ & $1.60 \pm 1.01$ & $1.94 \pm 1.66$ \\
\hline Literate & $2.58 \pm 1.36$ & $1.53 \pm 1.17$ & $1.52 \pm 0.85$ & $2.05 \pm 1.71$ \\
\hline & $\mathrm{p}=0.75$ & $\mathrm{p}=0.6$ & $\mathrm{p}=0.6$ & $\mathrm{p}=0.75$ \\
\hline Employement & & & & \\
\hline Housewife & $2.64 \pm 1.35$ & $1.60 \pm 1.1$ & $1.57 \pm 0.91$ & $2.00 \pm 1.68$ \\
\hline Working & $2.50 \pm 0.28$ & $1.30 \pm 1.8$ & $1.15 \pm 0.83$ & $2.33 \pm 2.31$ \\
\hline & $\mathrm{p}=0.88$ & $\mathrm{p}=0.9$ & $\mathrm{p}=0.37$ & $\mathrm{p}=0.73$ \\
\hline Type of Family & & & & \\
\hline Joint & $2.80 \pm 1.21$ & $1.64 \pm 1.1$ & $1.69 \pm 0.95$ & $1.92 \pm 1.64$ \\
\hline Nuclear & $2.31 \pm 1.51$ & $1.5 \pm 1.1$ & $1.32 \pm 0.86$ & $2.15 \pm 1.77$ \\
\hline & $\mathrm{p}=0.2$ & $\mathrm{p}=0.59$ & $\mathrm{p}=\mathbf{0 . 0 5}$ & $\mathrm{p}=0.5$ \\
\hline Number of Children & & & & \\
\hline$<=2$ & $3.08 \pm 0.91$ & $1.25 \pm 1.06$ & $1.36 \pm 0.87$ & $2.02 \pm 1.71$ \\
\hline$>2$ & $2.53 \pm 1.39$ & $1.70 \pm 1.14$ & $1.63 \pm 0.92$ & $2.00 \pm 1.69$ \\
\hline & $\mathrm{p}=0.29$ & $\mathrm{p}=0.10$ & $\mathrm{p}=0.19$ & $\mathrm{p}=0.9$ \\
\hline Socioeconomic status & & & & \\
\hline High & $2.73 \pm 1.08$ & $1.41 \pm 1.06$ & $1.43 \pm 0.90$ & $1.81 \pm 1.63$ \\
\hline low & $2.63 \pm 1.50$ & $1.76 \pm 1.20$ & $1.71 \pm 0.92$ & $2.26 \pm 1.74$ \\
\hline & $\mathrm{p}=0.8$ & $\mathrm{p}=0.16$ & $\mathrm{p}=0.14$ & $\mathrm{p}=0.2$ \\
\hline
\end{tabular}

The scores in the four domains of the MENQOL questionnaire in women with different sociodemographic characteristics were compared. It was found that in vasomotor domain, religion; and in sexual domain religion were predictors for better quality of life in menopausal women.

\section{Discussion}

Menopause is a transitional period that every woman goes through. The individual response to menopause and estrogen deficiency varies considerably due to genetic, cultural, lifestyle, socioeconomic, education and dietary factors. Menopause has emerged as a prominent issue in the women's health. We evaluated the quality of life of woman with menopausal symptoms on MenQoL. The aim of the present study was to assess the menopausal related symptoms and their impact on the women's quality of life. Several studies indicated that QOL was impaired in menopausal women because menopausal period is related with several physical and mental changes that may impact women's health outcomes.

In the current study, mean age of attaining menopause was found $45.80 \pm 4.49$ years and median age was 45 years which similar to some previous studies done elsewhere by Sagdeo and Arora in Nagpur, ${ }^{[10]}$ Poomala and Arounassalame in Puducherry, ${ }^{[12]}$ Sarkar et al. in Jamnagar, ${ }^{[13]}$ Bansal et al. in Punjab ${ }^{[14]}$ but lower than that found by Nisar and Sohoo in Sindh Pakistan ${ }^{[4]}$ where mean age was $52.17 \pm 6.019$ years.

Sagdeo and Arora in a comparative study in rural and urban women ${ }^{[10]}$ showed that most common problem was joint and muscular symptoms $(60.4 \%)$ followed by hot flushes and night sweats $(36.7 \%)$. In the current study, most prevalent symptoms reported were feeling tired, decrease stamina $(89 \%)$, feeling tired or worn out $(88 \%)$, change in sexual desire (84\%), avoiding intimacy $(82 \%)$, changes in appearance, texture or tone of skin $(70 \%)$, aching in muscle and joints $(69 \%)$ and experiencing poor memory (64\%). 
Mohamed et al. in Egypt ${ }^{[15]}$ showed that the most severe symptoms of vasomotor, psychosocial, physical and sexual domains were hot flushes (29\%), experiencing poor memory (48.3\%), being dissatisfied with their personal life $(44.8 \%)$, low backache $(41.9 \%)$, and change in sexual desire (36.8\%).However our study shows most severe symptoms in vasomotor, psychosocial, physical and sexual domains were hot flushes (48\%), experiencing poor memory (64\%), Feeling tired or worn out (88\%) and change in sexual desire (84\%) respectively.

Previous studies ${ }^{[16]}$ that evaluated the association between menopausal symptoms and sociodemographic and lifestyle factors, reported that lower socio-economic status, education, length of menopause, physical activity, working status, and age were related to QOL, however in our study that there was no statistical significant association between age, education, occupation, socioeconomic status, number of children and different symptoms of menopause.

\section{Conclusion}

A large proportion of postmenopausal women suffered from menopausal symptoms. The most common menopausal complaints reported by the postmenopausal women were feeling tired, decrease stamina, changes in appearance, texture or tone of skin, aching in muscle and joints and experiencing poor memory. Sexual life was also affected by menopause. Moreover, postmenpausal women suffered from depression and anxiety. In short almost all areas or domains evaluated were impaired in menopausal women.

Women need special care and attention in their postmenopausal period, this can be achieved by Education, creating awareness at both individual and community level and providing suitable intervention to improve the QOL in menopausal women.

There are several government policies that address women in their reproductive age group but there are none that caters to needs of women in post reproductive life. Thus government could concentrate on providing health services by incorporating components related to specific health needs of postmenopausal women in the national health programs.

\section{Recommendations}

The current study recommended that

1. Health care providers can play a very important role in continuously assessing post menopausal women's needs as well as implement appropriate health educational programs for women about the postmenopausal period and how to pass it safely.

2. Further research addressing women's health needs is also essential for improving the quality of life of postmenopausal women.

\section{Limitation of the study}

It was a cross sectional study thus temporal association between cause and effect cannot be established.

Moreover, Women were asked to recall symptoms and recall could be differentially biased based on different characteristics of women.

Funding: No funding sources

Conflict of interest: None declared

\section{References}

1. Padubidri VG, Daftary SN. Menopause. 13th ed. New Delhi: Reed Elsevier; 2006. Shaw's Textbook of Gynaecology; pp 5667.

2. Howkins J, Bourne G. Perimenopause, menopause, premature menopause and postmenopausal bleeding. In: Paduvidri VG, Daftary SN, editors. Shaw's Textbook of Gynaecology. 14th ed. India: Elsevier; 2008. p. 37.]

3. World Health Organization. Research on the menopause in the 1990s.Report of a WHO scientific group. World Health Organ Tech Rep Ser. 1996;866:1-107. [PubMed]

4. Nisar N, Sohoo NA. Frequency of menopausal symptoms and their impact on 
the quality of life of women: A hospital based survey. J Pak Med Assoc. 2009;59:752-6. [PubMed]]

5. Geneva: World Health Organization; 1981. Research on Menopause. Report of WHO Scientific Group. Technical Report Series 670.

6. World Health Organization. Research on the menopause in the 1990s. Report of a WHO scientific group. World Health Organ Tech Rep Ser. 1996;866:1-107.

7. New Delhi: Indian Menopause Society; Making Menopause Easier. Available from:

http://www.indiatogether.org/2006/0ct/wer e-menopause.htm .]

8. McKinney E, Ashwill J, Murray S, James S, Gorrie T, Droske S. Menopause. In: Mc Kinney E, Ashwill J, Murray S, James S, Gorrie T, Droske S. Menopause, eds. Maternal Child Nursing. St. Louis: Elsevier Science Health Science Division; 2012: 655.

9. Madhukumar S, Gaikwad V, Sudeepa D. A community based study on perceptions about menopausal symptoms and quality of life of post-menopausal women in Bangalore rural. Int $\mathrm{J}$ Health SciRes. 2012;2:49-56.]

10. Sagdeo MM, Arora D. Menopausal symptoms: A comparative study in rural and urban women. JK Sci J Med Educ Res. 2011;13:23-6

11. Soules MR, Sherman S, Parrott E, Rebar R, Santoro N, Utian W, Woods N. Executive summary: Stages of Reproductive Aging Workshop (STRAW). Fertil Steril 2001;76:874-8.

[11704104] [http://dx.doi.org/10.10 16/S00150282(01)02909-0]

12. Poomala GK, Arounassalame B. The quality of life during and after menopause among rural women. J ClinDiagn Res. 2013;7:135-9. [PMC free article] [PubMed]
13. Sarkar A, Pithadia P, Goswami K, Bhavsar S, Makwana NR, Yadav S, et al. A study on health profile of post-menopausal women in Jamnagar district, Gujarat. J Res Med Dent Sci. 2014;2:25-9.

14. Bansal P, Chaudhary A, Soni RK, Kaushal P. Menopausal problems among rural middle aged women of Punjab. Int $\mathrm{J}$ Res Health Sci. 2013;1:103-9.

15. Mohamed HA, Lamadah SM, Zamil LG. Quality of life among menopausal women. Int J Reprod Contracept Obstet Gynecol. 2014;3:552-61.

16. Assessment of Quality of Life in Menopausal Periods: A Population Study in Kashan, Iran 